\title{
MÁS ALLÁ DEL DERECHO A LA VIVIENDA
}

\author{
D. Rafael Arredondo Quijada \\ Decano del Colegio profesional de trabajo social de Málaga
}

Artículo Recibido: 15/01/2015

Artículo Aceptado: 20/02/2015

\section{Resumen}

La implicación y el compromiso desde la administración pública en el acceso de los ciudadanos a un hogar digno de cara a cumplir, no sólo la Constitución Española como requisito fundamental, sino el resto de normativas que así lo establecen (como el propio Estatuto de Andalucía, en su artículo 25); requiere desarrollar un conjunto de medidas destinadas especialmente a aquellas familias con menos recursos, para que puedan tener acceso a un hogar acorde con sus posibilidades económicas.

Pero el disponer de un hogar no es suficiente de cara a crear espacios habitables, cuya población no se encuentre en procesos de exclusión, ni pueda iniciarlos generando barrios en los que los recursos y las intervenciones necesarias para terminar con dichos procesos, superen con creces la inversión previa que hubiera sido necesaria para evitarlos, llegando incluso a perpetuarse los factores generadores de dicha exclusión.

Partiendo de esta realidad, una serie de medidas preventivas son planteadas. Estas medidas recogen qué otros aspectos deberían ser considerados cuando se produce el acceso a un hogar, de cara a generar comunidades insertadas tanto en su entorno como en el conjunto de la ciudad.

Una de estas medidas es la incorporación del Informe de Evaluación de Impacto Social como requisito previo a cada desarrollo urbanístico futuro. Este informe complementaría otros informes ya existentes como el de impacto ambiental o el de salud.

\section{Abstract}

The involvement and commitment from public administration on the access of citizens to a decent home in order to comply, not only the Spanish Constitution as an essential requirement, but the rest of regulations that establish it (like the Statute of Autonomy of Andalusia, in its Article 25); requires to develop a set of measures designed especially to families with fewer resources, so they can have access to a home in accordance with their economic possibilities.

But having a home is not enough in order to create habitable spaces, whose population is not in exclusion processes, neither can initiate them creating neighbourhoods where resources and interventions needed to end these processes, far exceed the previous 


\section{WPS Review International on Sustainable Housing and Urban Renewal (RI-SHUR)}

investment which would have been necessary to avoid them, even perpetuating the factors that generate such exclusion.

Given this reality, a set of preventive measures are proposed. These measures take up what other issues should be considered when access to a home occurs, in order to generate communities inserted both in their environment as in the whole of the city.

One of these measures is the incorporation of the Social Impact Assessment Report as a prerequisite to each future urban development. This report would complement others already existing like the environmental impact report or health report.

\section{Más allá del acceso a la vivienda}

El objetivo de ésta publicación va a estar centrado en: valorar que otros aspectos son necesarios cuando se produce el acceso a la vivienda, para generar comunidades insertas tanto en su entorno como en el conjunto de la ciudad. Evitando de ésta forma posibles procesos de exclusión social.

Quien no ha oído hablar en Málaga de Los Asperones, o de la Palma-Palmilla o de la Corta, o de García Grana y los Palomares, y casi automáticamente se viene a la mente zonas con delincuencia, con problemas de adicciones, con falta de formación, con desempleo. En definitiva población situada en la marginación y/o exclusión, ya que todos estos factores conllevan o llevan a ello, Subirats (2004, p.12).

Tal y como indica la Fundación FOESSA, a la hora de abordar la exclusión social, no cabe duda de que son los ámbitos del empleo, de la vivienda y de la salud los que más han aportado al aumento de la fractura social.

Para realizar un acercamiento sobre la realidad de estos barrios, se recoge las características que de los mismos incorpora el VI Plan de Inclusión Social del Ayuntamiento de Málaga 2014-2018, aprobado con fecha del 31 de julio de 2014.

\begin{tabular}{|l|ll|}
\hline \multirow{4}{*}{ Asperones } & - & Barriada de transición \\
& - & Creada en 1987 \\
& - & 185 viviendas \\
& - & Familias en riesgo de exclusión social \\
& - & En el año 2008, los datos actualizados del censo, informan \\
& & que existen 178 viviendas, con 69 ampliaciones de las \\
& mismas, como viviendas independientes y 17 chabolas, ésta \\
& & últimas principalmente en la tercera fase \\
\hline \multirow{4}{*}{ La Corta } & - & Barriada de transición \\
& - & Creada en 1994 \\
- & 220 viviendas \\
& - & Una característica común de esta población es su \\
& procedencia de otras zonas de exclusión y, en algunos \\
& casos, la falta de un lugar de residencia fijo durante periodos \\
& de tiempo prolongados, lo que originó una inestabilidad y \\
\hline
\end{tabular}




\section{WPS Review International on Sustainable Housing and Urban Renewal (RI-SHUR)}

\begin{tabular}{|c|c|}
\hline & desarraigos característicos \\
\hline $\begin{array}{l}\text { García Grana } \\
\text { Palomares }\end{array}$ & $\begin{array}{l}\text { - } 500 \text { viviendas en régimen de alquiler pertenecientes al IMV } \\
\text { (Instituto Municipal de la Vivienda) } \\
\text { - } 325 \text { viviendas en régimen de alquiler pertenecientes a la } \\
\text { Junta de Andalucía } \\
\text { - } \quad \text { En estas barriadas residen } 3.985 \text { habitantes, de ellos un } \\
71,74 \% \text { de personas son demandantes de empleo } \\
\text { - } \quad \text { Barriada con una elevada aglomeración de viviendas } \\
\text { sociales, pertenecientes al Distrito de Cruz de Humilladero } \\
\text { - La droga es el principal problema de las familias del barrio, } \\
\text { seguido del paro. La inseguridad ciudadana y los problemas } \\
\text { con la justicia dan lugar a conflictividad vecinal }\end{array}$ \\
\hline $\begin{array}{l}\text { Las } \\
\text { Castañetas }\end{array}$ & $\begin{array}{ll}\text { - } & \text { Creada en } 1992 \\
\text { - } & 180 \text { viviendas } \\
\text { - } & \text { La mayoría de las familias que se encuentran en un proceso } \\
& \text { de exclusión social son las que habitan las viviendas } \\
& \text { sociales, que se concentran en } 17 \text { calles }\end{array}$ \\
\hline Palma-Palmilla & $\begin{array}{l}\text { - } \begin{array}{l}\text { Zona con Necesidades de Transformación Social, constituida } \\
\text { - }\end{array} \text { La Palma barriadas: } \\
80 \\
\text { - } \quad \text { La Palmilla- } \rightarrow \text { construida a principios de la década de los } 60 \\
\text { - } \quad \text { La Virreina- } \rightarrow \text { construida en } 1961 \\
\text { - } \quad 720 \text { Viviendas- } \rightarrow \text { origen en los años } 70-80 \\
\text { - } \quad 26 \text { de Febrero- } \rightarrow \text { construida a finales de los años } 50 \\
\text { - } \quad \text { Unidades de viviendas adosadas UVA- } \rightarrow \text { su origen es } \\
\text { paralelo a La Palma } \\
\text { - Con un total de población de } 15.160 \text { personas } \\
\text { - } \quad \text { La problemática y demanda social en el distrito ha sufrido } \\
\text { una considerable transformación y aumento en los últimos } \\
\text { años: personas que no tienen cubiertas sus necesidades } \\
\text { básicas (comida, vivienda ...) niños, niñas y mayores en } \\
\text { situación de grave riesgo social, familias sin recursos } \\
\text { económicos, sectores inmersos en proceso de exclusión } \\
\text { social (jóvenes y mujeres), etc. } \\
\text { Muchas de las personas que viven en esta zona de la ciudad } \\
\text { se encuentran en situación de pobreza severa; es decir, } \\
\text { disponen de menos de } 160 \text { euros al mes para mantenerse, o } \\
\text { lo que es lo mismo, menos de } 5,3 \text { euros al día }\end{array}$ \\
\hline Distrito & $\begin{array}{l}\text { - Zonas con Necesidades de Transformación Social, que se } \\
\text { viene desarrollando desde el año } 2000\end{array}$ \\
\hline
\end{tabular}

Tabla 1. Características de los barrios

Fuente: VI Plan de Inclusión Social del Ayuntamiento de Málaga 2014-2018 


\section{WPS Review International on Sustainable Housing and Urban Renewal (RI-SHUR)}

Este perfil de las diferentes zonas de Málaga con carga, en algunas bastante, de vivienda social, confirma lo indicado por Trilla (2001, p.80-81) a la hora de abordar las principales problemáticas detectadas en los parques sociales públicos:

- mala gestión financiera y gasto público excesivo;

- mala conservación de los edificios;

- creación de sectores de segregación: concentración de parados y de personas mayores;

- en los sistemas que plantean más dificultades a la permanencia en el alquiler y que, por tanto, potencian una mayor movilidad, concentración creciente (en los últimos diez años) de colectivos pobres: parados, familias monoparentales, minorías étnicas, inmigrantes, con la creación de segmentos de segregación;

- en los sistemas que hacen más fácil la permanencia en el alquiler (con subvenciones elevadas), freno a la movilidad en casos de hogares con rentas medias que podrían optar a viviendas mejores; $y$

- creación de <<trampas de pobreza >>, con el mantenimiento de personas que prefieren mantenerse en paro para seguir teniendo derecho a la vivienda o a la subvención.

Donde se reconoce en general que la concentración de familias desfavorecidas en determinados barrios de las ciudades es un problema grave y un factor importante de trastornos sociales. A la vez que desde hace tiempo se admite que la vivienda de buena calidad es esencial para el desarrollo de la cohesión social en los países europeos; en este campo, los objetivos y las concepciones de la política de vivienda han evolucionado con el tiempo y difieren de un país a otro; la política de vivienda influye directamente sobre un $15 \%$ de los hogares de los países mediterráneos y sobre el $50 \% / 60 \%$ de los nórdicos más acomodados. Trilla (2001, p. 139-142)

Pero si en Málaga tenemos estos barrios con estas características, tristemente en cada una de las provincias andaluzas también existen barrios muy parecidos, o incluso en algunas de ellas en peores condiciones.

Esta circunstancia originó que la Junta de Andalucía aprobara en 1989 el Decreto $202 / 1989$, de 3 de octubre, por el que se crea el plan de barriadas de actuación preferente, incluyéndose en dicho decreto las siguientes barriadas del conjunto de Andalucía:

- El Puche en Almería

- La Paz-Puntales en Cádiz

- Las Moreras en Córdoba

- Cartuja-Almanhayar en Granada

- Marismas del Odiel en Huelva

- La Magdalena-San Vicente de Paul en Jaén

- Palma-Palmilla en Málaga 


\section{WPS Review International on Sustainable Housing and Urban Renewal (RI-SHUR)}

- Polígono Sur en Sevilla

En el citado decreto se indica como alguna de las consecuencias de la situación de marginación y exclusión que sufren estas barriadas es el modelo dominante de desarrollo urbano y una, a veces, inadecuada planificación en los asentamientos, indicando que sufren las consecuencias del hacinamiento, síntomas de la disgregación, la marginación, las disfunciones del desarrollo y los efectos de las conductas delictivas.

Donde a la hora de abordar la intervención en estas zonas se alude a cuatro áreas: formación, animación socio-cultural, inserción social y urbanismo, infraestructura y vivienda.

Se puede comprobar como el factor urbanístico relacionado con la vivienda, juega un papel importante de cara a que las personas que posteriormente van a ocupar estas zonas tengan un mayor o menor riesgo de exclusión social. Pero no sólo en cuanto a la vivienda en sí, desde sus características más específicas, sino en lo que al aspecto de desarrollo urbanístico del entorno, y la puesta en marcha de una serie de servicios mínimos para que se facilite una adecuada convivencia.

Pero si el decreto del año 1989 establecía ocho barriadas, una por cada provincia andaluza, con una serie de características de riesgo de cara a la exclusión social, que las hacía situarse como de actuación preferente. Veinticuatro años después y según recoge el Decreto-Ley $7 / 2013$, de 30 de abril, de medidas extraordinarias y urgentes para la lucha contra la exclusión social en Andalucía, en su anexo I, se contemplan un total de veinte barriadas que son consideras por la administración como Zonas de Transformación Social. 


\section{WPS Review International on Sustainable Housing and Urban Renewal (RI-SHUR)}

\begin{tabular}{|c|c|c|}
\hline Provincia & Municipio & \\
\hline JAÉN & JAÉN & $\begin{array}{l}\text { BARRIOS DE SAN VICENTE DE PAÚL, ANTONIO DÍAZ Y SECCIÓN } \\
\text { CUARTA DEL DISTRITO VI DE LA MAGDALENA }\end{array}$ \\
\hline JAÉN & ANDÚJAR & POLÍGONO PUERTA DE MADRID \\
\hline JAÉN & LINARES & BARRIOS DE EL CERRO, ZARZUELA Y SAN ANTONIO \\
\hline MÁLAGA & MÁLAGA & $\begin{array}{l}\text { DISTRITO CENTRO (CAPUCHINOS, CRUZ VERDE, LAGUNILLAS, } \\
\text { CALLE ALTA, PLAZA DE LOS CRISTOS, MARISCAL Y TRINIDAD Y } \\
\text { PERCHEL) }\end{array}$ \\
\hline MÁLAGA & MARBELLA & BARRIADA LAS ALBARIZAS \\
\hline MÁLAGA & RONDA & BARRIADA LA DEHESA-EL FUERTE \\
\hline MÁLAGA & VÉLEZ-MÁLAGA & PUEBLO NUEVO DE LA AXARQUÍA \\
\hline MÁLAGA & VÉLEZ-MÁLAGA & LA GLORIA \\
\hline MÁLAGA & VÉLEZ-MÁLAGA & CUESTA DEL VISILLO \\
\hline MÁLAGA & VÉLEZ-MÁLAGA & NÚCLEO CASAS DE LA VÍA \\
\hline SEVILLA & SEVILLA & POLÍGONO SUR \\
\hline SEVILLA & SEVILLA & TORREBLANCA \\
\hline SEVILLA & SEVILLA & POLÍGONO NORTE \\
\hline SEVILLA & SEVILLA & TRES BARRIOS-AMATE \\
\hline SEVILLA & SEVILLA & EL VACIE \\
\hline SEVILLA & ALCALÁ DE GUADAÍRA & $\begin{array}{l}\text { ZONA ESTE (TONELEROS, PINTOR JUÁN VALDÉS LEAL, BERNARDO } \\
\text { DE LOS LOBITOS, PINTOR LUNA RUBIO, JOSÉ VÁZQUEZ VAL, JUÁN } \\
\text { DE DIOS DÍAZ, DIRECTOR PÉREZ VÁZQUEZ, MAESTRO MANUEL } \\
\text { PALACIOS GANDULFO Y MAESTRO JOSÉ CASADO) }\end{array}$ \\
\hline SEVILLA & ALCALÁ DE GUADAÍRA & $\begin{array}{l}\text { ZONA SUR (SAN FERNANDO, CADOSO, SAN MIGUEL, SANTA } \\
\text { MARÍA, ALMENA, ARRABAL, LAS TORRES, SÁNCHEZ PERRIER, } \\
\text { TAJO, EBRO, BANDERA, MEDIALUNA Y PLAZA DEL CONGRESO) }\end{array}$ \\
\hline SEVILLA & ALCALÁ DE GUADAÍRA & $\begin{array}{l}\text { ZONA NORTE (SÁNLUCAR LA MAYOR, MARÍA ZAMBRANO, VILLA } \\
\text { DE ROTA Y PELAY CORREA-SAN RAFAEL Y LA LIEBRE) }\end{array}$ \\
\hline SEVILLA & DOS HERMANAS & $\begin{array}{l}\text { IBARBURU, COSTA DEL SOL, LA JARANA, MIRAVALLE, LOS } \\
\text { MONTECILLOS, EL CHAPARRAL Y CERRO BLANCO }\end{array}$ \\
\hline SEVILLA & SAN JUAN DE AZNALFARACHE & BARRIADA DE SANTA ISABEL \\
\hline
\end{tabular}

Anexo I. Decreto-Ley $7 / 2013$, de 30 de abril, de medidas extraordinarias y urgentes para la lucha contra la exclusión social en Andalucía

Habiendo sido ratificadas estas zonas en el más aún reciente Decreto-Ley $8 / 2014$, de 10 de junio, de medidas extraordinarias y urgentes para la inclusión social a través del empleo y el fomento de la solidaridad en Andalucía, según se recoge en la Disposición derogatoria 2:

"Asimismo, se mantiene en vigor la definición de $<$ ZZonas con Necesidades de Transformación Social >> que se establece en el artículo 3.3 y lo dispuesto en el artículo 3.4 del Decreto ley/2013 de 30 de abril, así como su Anexo l"

Recogiendo la definición que de Zonas con Necesidades de Transformación Social realiza la Consejería de Igualdad, Salud y Políticas Sociales, define a estas como aquellos espacios urbanos claramente delimitados, en cuya población concurran situaciones estructurales de pobreza grave y marginación social, y en los que sean significativamente apreciables problemas en las siguientes materias: 


\section{WPS Review International on Sustainable Housing and Urban Renewal (RI-SHUR)}

- Vivienda, deterioro urbanístico y déficit de infraestructura, equipamiento y servicios públicos.

- Elevados índices de absentismo y fracaso escolar.

- Altas tasas de desempleo junto a graves carencias formativas profesionales.

- Significativas deficiencias higiénicas sanitarias.

- Fenómenos de desintegración social.

La vivienda y lo que la rodea en cuanto a desarrollo urbanístico, infraestructuras, equipamientos y servicios se sitúa como ítem a tener en cuenta a la hora de definir y catalogar este tipo de barriadas, incorporando aquellas que se encuentran con un mayor déficit para hacerlas objeto del desarrollo de posteriores intervenciones sociales.

Habría que plantear que elementos preventivos se están teniendo en cuenta, siendo conocedores de las circunstancias que a posteriori generan procesos en donde determinados territorios terminan teniendo que ser calificados como Zonas de Transformación Social. Habida cuenta del incremento de estas zonas en el conjunto de Andalucía, se podría concluir que éstas medidas preventivas o no se han implantado o es que no se han llegado a desarrollar.

En la actualidad se hace necesario y en algunos territorios urgente, una política en palabras del arquitecto Beltrán (2002, p. 65) cualitativista, que analice los efectos de las actuaciones sobre el tejido urbano y social existente, y las dirija a conseguir el máximo beneficio en términos globales, resolviendo con la inversión pública al mismo tiempo asuntos indisociables que no admiten tratamiento separado, salvo que se quiera vestir un santo desnudando a otro.

Pero si efectivamente se hace necesario y así se viene realizando desde 1989, intervenciones lo más integrales posibles en el ámbito social de cara a solventar los problemas que estas barriadas sufren desde diferentes áreas, sería casi de obligado cumplimiento el que nuevos desarrollos urbanísticos, a tenor de lo que ya se conoce, no cometieran los mismos errores del pasado. Siendo conscientes de que la exclusión social es sobre todo un fenómeno urbano, y que dentro de las ciudades, incluso de las prósperas, la exclusión se localiza especialmente en zonas y barrios concretos Algunos países asocian la concentración de población fragilizada (sobre todo personas mayores solas e inmigrantes) a barrios degradados y con pocos servicios de los centros urbanos. Otras veces se asocia a zonas de viviendas sociales o económicas de la periferia. Aguirre (2011, p. 23).

\section{Propuestas y conclusiones}

Ante desarrollos urbanísticos nuevos, sean estos realizados en régimen libre o de vivienda protegida (en sus diferentes características), debieran de contemplar todos ellos una serie de servicios adicionales, haciéndose un mayor hincapié en aquellos entornos donde se prevea que la población a ocupar los mismos, pudiera estar en situación de generar posibles realidades de exclusión en función de su características 


\section{WPS Review International on Sustainable Housing and Urban Renewal (RI-SHUR)}

y circunstancias personales. Ya que los espacios urbanos donde residen los ciudadanos son contextos territoriales que fomentan la inclusión social o la seguridad entre otros. Toset $(2011$, p. 38)

Estos servicios adicionales, podrían pasar por equipos de mediadores vecinales $y$ comunitarios, que vendrían a favorecer en un primer momento la dinamización, el conocimiento y la convivencia entre los nuevos residentes, generando redes de empoderamiento a fin de favorecer la resolución de cualquier problema que pueda surgir en la comunidad.

Sin olvidar el que exista una adecuada integración de las viviendas con el entorno, en donde no sean estas vistas como algo ajeno al mismo. Generando una integración en donde los titulares se comprometan tanto con el mantenimiento de sus viviendas, como con el entorno que les rodea, sintiéndose parte de un todo común. Para ello la utilización de materiales que hagan fácil su mantenimiento, a la vez que económico, son elementos que vendrían a favorecer este compromiso del residente con su vivienda y el entorno.

Pero como elemento preventivo y a plantear de buenas prácticas de cara a futuros procesos urbanísticos en territorios aún sin desarrollar, el que se pudiera crear la figura administrativa del Informe de Evaluación de Impacto Social, como instrumento y herramienta que viniera a medir posibles riesgos en su ámbito (social). De cara a facilitar toda una serie de información necesaria para que pueda ser recogida y de manera anticipatoria en la planificación y diseño del nuevo espacio territorial. Al igual que los ya existentes:

Informe de Evaluación Ambiental, definido en la actual Ley 21/2013, de 9 de diciembre, de evaluación ambiental como: procedimiento administrativo instrumental respecto del de aprobación o de adopción de planes y programas, así como respecto del de autorización de proyectos o, en su caso, respecto de la actividad administrativa de control de los proyectos sometidos a declaración responsable o comunicación previa, a través del cual se analizan los posibles efectos significativos sobre el medio ambiente de los planes, programas y proyectos. La evaluación ambiental incluye tanto la <evaluación ambiental estratégica>> como la <evaluación de impacto ambiental >>.

El Informe de Evaluación de Impacto en Salud, recogido en la Ley 16/2011, de 23 de diciembre, de Salud Pública de Andalucía, donde en su artículo 2.15 lo define como: Informe emitido por la Consejería competente en materia de salud, sobre la valoración del impacto en la salud realizada a un plan, programa, instrumento de planeamiento urbanístico, obra o actividad

Habiendo sido aprobado recientemente el contenido y su metodología a la hora de evaluar el impacto de la salud, a través del Decreto 160/2014, de 9 de diciembre, por el que se establece el procedimiento de la Evaluación del Impacto en la Salud de la Comunidad Autónoma de Andalucía.

Este Informe de Evaluación de Impacto Social, que pudiendo ser elaborado y emitido por una entidad de derecho público como son los colegios profesionales de Trabajo 


\section{WPS Review International on Sustainable Housing and Urban Renewal (RI-SHUR)}

Social, o por la propia administración desde la consejería correspondiente, vendrían a cubrir una realidad que en estos momentos aun siendo consciente de ella no se aborda, como es la realización de una planificación urbana más integral. Donde acorde con las problemáticas ya conocidas, en muchos de los casos se pudieran y/o evitar 0 disminuir su impacto, tanto social como económico. Ya que no se puede olvidar que la inversión social en procesos de inclusión social, conlleva costes mucho más elevados que si ésta es abordada de manera preventiva en sus orígenes.

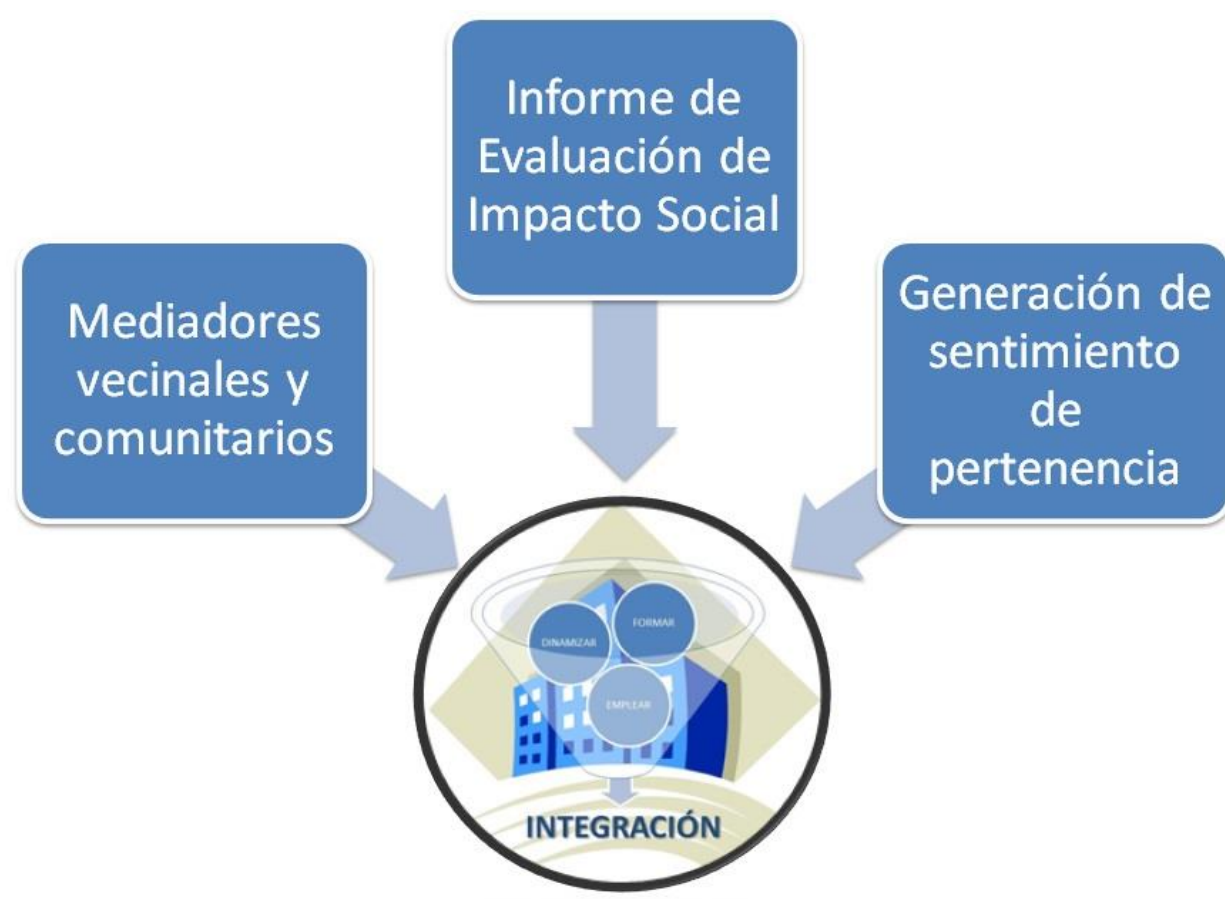

\section{Bibliografía}

AGUIRRE, P. (2011). Nuevas alternativas de viviendas social. Revista de Servicios Sociales y Política Social, 97, 21-35

BELTRÁN, R. (2002). De aquellos barros, estos lodos. La política de vivienda en la España franquista y postfranquista. Acciones e Investigaciones Sociales, 16, 25-67

Boletín Oficial de la Junta de Andalucía. Decreto 202/1989, de 3 de octubre, por el que se crea el plan de barriadas de actuación preferente. Recuperado el 26 de octubre de 2014 http://www.juntadeandalucia.es/boja/1989/79/1

Boletín Oficial de la Junta de Andalucía. Ley 16/2011, de 23 de diciembre, de Salud Pública de Andalucía. Recuperado el 8 de noviembre de 2014 http://www.juntadeandalucia.es/boja/2011/255/d4.pdf

Boletín Oficial de la Junta de Andalucía. Decreto 7/2013, de 30 de abril, de medidas extraordinarias y urgentes para la lucha con la exclusión social en Andalucía. 


\section{WPS Review International on Sustainable Housing and Urban Renewal (RI-SHUR)}

$\begin{array}{llllll}\text { Recuperado el } & 8 & \text { de } & \text { noviembre } & \text { de } & 2014\end{array}$ http://www.juntadeandalucia.es/boja/2013/85/BOJA13-085-00062-7379-

01 00026320.pdf

Boletín Oficial de la Junta de Andalucía. Decreto 8/2014, de 10 de junio, de medidas extraordinarias y urgentes para la inclusión social a través del empleo y el fomento de la solidaridad en Andalucía. Recuperado el 8 de noviembre de 2014 http://www.juntadeandalucia.es/boja/2014/113/BOJA14-113-00071-10208-

01 00049694.pdf

Boletín Oficial de la Junta de Andalucía. Decreto 169/2014, de 9 de diciembre, por el que se establece el procedimiento de la Evaluación del Impacto en la Salud de la Comunidad Autónoma de Andalucía. Recuperado el 27 de diciembre de 2014. http://www.juntadeandalucia.es/boja/2014/243/2

Boletín Oficial del Estado. Ley 21/2013, de 9 de diciembre, de evaluación ambiental.

$\begin{array}{llllll}\text { Recuperado el } & 8 & \text { de } & \text { noviembre }\end{array}$

https://www.boe.es/boe/dias/2013/12/11/pdfs/BOE-A-2013-12913.pdf

Consejería de Igualdad, Salud y Políticas Sociales. Zonas de transformación social. $\begin{array}{llllll}\text { Recuperado el } & 08 & \text { de } & \text { noviembre } & \text { de } & 2014\end{array}$ http://www.juntadeandalucia.es/organismos/igualdadsaludypoliticassociales/areas/inclu sion/zonas-transformacion/paginas/zonas-intervencion.html

VI Plan Municipal de Inclusión Social del Ayuntamiento de Málaga 2014-2018. Área de Derechos Sociales. Ayuntamiento de Málaga

Precariedad y Exclusión Social. Avance de resultados de la Encuesta sobre integración y Necesidades Sociales, 2013. Fundación FOESSA, 2014

Subirats, J. (Director). (2004). Pobreza y esclusión Social. Un análisis de la realidad española y europea. Colección Estudios Sociales, 16. Barcelona. Fundación la Caixa

Toset, J. (2011). Derechos humanos y viviendas en España. El papel del Trabajo Social en las políticas de vivienda. Revista de Servicios Sociales y Política Social, 97, 37-46

Trilla, C. (2001). La política de vivienda en una perspectiva europea comparada. Colección 